[Penetito, W., \& Sanga, K. (2003). A Conversation on the Philosophy and Practice of Teaching Research in Māori and Pacific Education. New Zealand Annual Review of Education, 12, 21-37]

\section{A Conversation on the Philosophy and Practice of Teaching Research in Māori and Pacific Education}

\section{WALLY PENETITO AND KABINI SANGA}

\section{Abstract:}

Research in Māori and Pacific education based on Māori and Pacific philosophies and practices is a new endeavour for tertiary institutions in New Zealand. In this article, the authors describe one such course which they teach to education masters' students at Victoria University of Wellington. They argue that such courses must be concerned to address the philosophical bases of research at least as rigorously as the methods used to investigate matters of enquiry. It is claimed that Māori and Pacific peoples are demanding the sort of research that helps them to survive, to contribute, and "to be" in the world as Māori and Pacific peoples.

$\mathrm{R}$ esearch in the Māori and Pacific fields has developed rapidly in recent years. Within New Zealand there is evidence to suggest that the development is related to an increasing number of Māori and Pacific students enrolling in masters and doctorate degrees where research is a requirement (Massey University, 1998). As expected, these students will have read and studied a number of research reports long before they entered their higher degree courses, and would have acquired reasonably informed views about research, especially as it pertains to Māori and Pacific peoples. The students perceive the need to research in their own fields (Māori and Pacific) and to do so using techniques and approaches that sit philosophically and methodologically within those fields (Royal, 1992; Bishop, 1996). At the same time they also realise the wisdom of "having one foot inside and another outside" the existing research paradigms (Smith, 1999). The course discussed in this article is one attempt to meet the needs of students intending to engage in educational research with Māori and Pacific communities.

In 1999 the School of Education at Victoria University of Wellington introduced an MEd course entitled, "Research as Praxis: Māori and Pacific Nations Education". At the time the School already offered two other generic research courses, one at undergraduate level, "Education Research Methods" and the other, a compulsory graduate course for students intending to complete an MEd by thesis, "Research Methods in Education". This article is mainly about the course, "Research as Praxis: Māori and Pacific Nations Education" referred to hereafter as Research as Praxis or RAP.

Research as Praxis is described as the way the two lecturers see the course, in the form of a "conversation" around some of the key concerns which have arisen over the five years the course has been taught. Wally Penetito first taught the course with Dr 'Ana Koloto in 1999 and from 2000 to 2002, with Dr Kabini Sanga.

According to the original description, the course was designed to enable educators to explore the issues related to the relationship between research and praxis in the context of Māori and Pacific Nations development. A major theme of the course was to study the way in which indigenous communities within Aotearoa New Zealand and the wider Pacific basin become politicised in their responses to the research and scholarship enterprise. A second theme in the course was the articulation of indigenous knowledge with theoretical explorations of those.

The course was designed so that students should be able to meet five objectives:

- To explain key concepts, themes and perspectives related to research in Māori and Pacific nations education in Aotearoa New Zealand;

- To have a basic understanding of the research literature as it relates to Māori, Pacific nations and other indigenous peoples;

- To identify the practices within the research culture which help politicise Māori and Pacific Nations educators,

- To have an in-depth understanding of the most appropriate research methods to apply in an investigation of indigenous Māori and Pacific Nations knowledge; and

- To critique items of conventional research on indigenous, Māori and Pacific nations peoples using theoretical frameworks derived from indigenous sources. 


\section{The Questions Discussed}

To provide a framework for the conversation, the authors agreed to keep their comments within the parameters of research paradigms outlined in the article by Guba and Lincoln (1994). There are six questions the conversationalists will answer on Māori and Pacific educational research. They will answer each question independently, but will alternate as to who answers each question first. The conversation will conclude with a joint summary and synthesis.

\section{Q1. What do you mean when you talk about "M ori/Pacific education"?}

WP: When I think about Māori and Pacific education I have three inter-related activities in mind:

Firstly, the lifelong enculturation of Māori and Pacific peoples into the values, norms, and customs of their respective ethnic communities. Most of this happens within the family, the church, the village and the marae. It begins at birth (and even before birth for some people) and ends at death. It answers the question: "What does it mean to be Māori/Fijian/Niuean, etc.?"

Secondly, there is the process of socialisation of Māori and Pacific peoples into the values, norms and customs of formal "mainstream" schooling. I am using mainstream to describe the schooling process because of the pervasiveness of the dominant Western culture in the school systems, whether these are located in Aotearoa or in the Pacific, whether today or in the past. The culture of mainstream schooling in my experience is a hegemonic experience. The process of schooling answers the question: "How do I get to know about the wider world?"

Thirdly, is the process of education of Māori and Pacific peoples into the integration of the above two activities. It is this integration of lifelong enculturation and formal socialisation into the everyday life of schooling that is the critical path of education. Whereas much of enculturation can and does occur as though through a process of osmosis, like learning to speak one's own first language, socialisation into schooling opens up whole new ways of seeing and explaining the way the world works, as well as challenging, quite often for the first time, the world one has already learned to take for granted as reality. However, if this socialisation does not find affinities, consistencies and continuities with the earlier processes of enculturation, what frequently results is mis-learning (students have difficulty finding relevance in the learning - "What is the point of learning about the Battle of
Bannockburn?"), un-learning (students prioritise school learning over home learning-"The teacher said Te Kooti was a rebel and you told me he was our hero"), and negative learning (students learn that learning separates them from their communities - "Who wants to be a Māori I'd rather be a Pākehā - it makes life easier"). The practicalities that derive from discovering affinities, consistencies, and continuities between home-life and school-life is what I mean by the integration of these two spheres of activity. Education into the wider world of values, norms and customs becomes possible for Māori and Pacific students when the integration of community enculturation and the processes of socialisation into schooling are operating at a level of critical consciousness, that is, when those involved know how and why the present system came about and how it can be challenged in the light of contemporary social, cultural and educational need.

KS: In the New Zealand context, it is education for and of peoples with a Pacific heritage who are residents and citizens of Aotearoa New Zealand. Except for the schooling experiences in Pasifika early childhood centres, the educational experiences of the students of Pacific heritage in schools and tertiary institutions are largely a socialisation into "mainstream culture." While a few are likely to succeed in this system, the majority of students of Pacific heritage will not, primarily because of the incompatibility of this system with the cultures of Pacific students and the resistance of Pacific communities to outright assimilation into the mainstream culture, represented by institutionalised schooling. Much of the attention by government, schools, researchers, and the education community is on the problematics of this situation, rather than on educating of Pacific students for life-long enculturation, as Penetito puts it.

At another level, it is education in, of and for peoples of the different Pacific Island countries. Again, Pacific education in this sense is equated with institutionalised schooling, a system that is imported wholesale (Thaman, 2002) and fundamentally different from village life (Roughan, 2002). Despite the attention given it for decades, this education, in all Pacific Island countries, as observed by Taufe' ulungaki (2002), has largely failed to meet the development needs of Pacific communities because it has neglected to address underlying issues of the nature of education in the Pacific context, its purposes and visions within this context. The beginnings of a healthy discourse on Pacific education are currently seen, particularly among Pacific peoples 
themselves. If encouraged, the discourse has the potential of informing our understanding of the recurring problematics of institutionalised schooling.

At yet another level, it is education that is Pacific in substance, form and medium. In this regard, Pacific nations education is that which is Pasifika-in-nature because it is rooted in the values, cosmologies, realities and cultures of these peoples, whether they live in Aotearoa, Rarotonga, Tuvalu or anywhere else. These values and realities do change, embracing additions and adoptions seen as relevant to Pacific communities.

The main purpose of this education, as suggested by Pacific educators (Taufe'ulungaki, 2002) is the survival, transformation and sustainability of Pacific peoples and their cultures. It also includes, as pointed out earlier by Penetito, preparing Pacific peoples for the wider world.

The relevance of Pasifika education is pan-Pacific but the phenomenon is distinctly Samoan, Tongan or Nauruan. This makes Penetito's point about the need to be critically conscious very important, because without that, education cannot be reflective of Nauruan or Samoan needs for enculturation and socialisation of its members for the wide world.

\section{Q2. "Research as praxis" will leave many people grasping for} comprehension. Why that title?

KS: Within Pacific peoples' knowledge systems, research is an activity - a "doing thing", as opposed to being an internal - a "thinking thing" (mind issue) only. Research is also a purposive activity towards community good, rather than merely a good, interesting thing to do. It is pragmatic and is not a stand-alone activity, but one that is integral to the ways of life and practice of Pacific communities and influenced by these. The title draws attention to the importance of critically linking research to the educational experiences of Pacific peoples, using appropriate tools of study that ensure that rigorous critique takes place.

WP: The concept of "praxis" is probably best known among Māori and Pacific students through the works of Paulo Freire, especially Pedagogy of the Oppressed (1977). Judging by the Māori and Pacific students who quote this work in their assignments, there is little doubt that the notion of "praxis" is seen as an important catalyst for critically examining the often neglected relationship between theory and practice. It is unfortunate that few Māori and Pacific students get to study, or opt to study, critiques of schooling such as those by Marxists or the deschoolers, although it is easy to understand their reasons. The scholars from these fields seem determined to correspond with each other without concern for those who find their intensive theorising more mystifying than revealing.

However, the point about studying any critique of schooling is that it will highlight a vocabulary for talking and thinking about schools for those who have not shared its positive experiences. Concepts like hegemony, symbolic violence, cultural capital and of course "praxis" provide them with tools which when sharpened are able to cut through the illusions that dog their negative schooling lives. Interpreting praxis as merely "reflection on practice" does not get to the heart of it. Praxis is as central to a Marxist epistemology, as Sanga reminds us, as it is to Māori and Pacific experiences of education. The account by the American professor of education, Kenneth A. Strike (1989) is a useful interpretation at this point. Strike, quoting from Marx's Theses on Feuerbach, claims that praxis tells us that:

The question of whether objective truth can be attributed to human thinking is not a question of theory but is a practical question. Man must prove the truth, that is the reality and power, the this-sidedness of his thinking in practice. The dispute over the reality or non-reality of thinking which is isolated from practice is a purely scholastic question. (p. 67)

As every teacher knows, activity not contemplation, is central to knowing. But not any kind of activity is at the heart of the process of knowing - it is activity which builds on what it means "to be" Māori, Samoan, Cook Islander, and so on, that is the crucial activity. This is the task both lecturers and students must engage in for this to be an RAP course in deed, as well as on paper.

Q3. Indigenous peoples all over the world accuse the colonisers of subjecting them to rigorous scrutiny through research, yet minimal benefit seems to accrue to the former. What is your comment about this, and if it is true, then how can this be turned to the advantage of indigenous peoples?

WP: The nineteenth century colonising nations of Europe swept through the Pacific and Africa annexing "empty" lands and the indigenous peoples who had resided in those lands for centuries and 
sometimes for millennia. Throughout the twentieth century many of these indigenous peoples have become the disenfranchised of their own homelands, and all, without exception, suffer to various degrees "conditions of separation" characterised as problems of identity, often as a result of alienation from traditional homelands and culture, as well as being divided from traditional sources of authority and control. These conditions of separation become manifest in a variety of abuses experienced in everyday life, as people struggle to survive and hold onto their remaining vestiges of hope and dignity.

It is no surprise that Māori, Australian Aboriginal, Hawaiian, Native American, and Canadian Inuit peoples share so much in common. As indigenous peoples they share ideas and values:

- of inclusiveness (tatou tatou);

- of the connectedness of all things (whakapapa);

- reflecting a preference for the collective life over the individualistic (nau te rourou, naku te rourou ka ora ai tatou);

- of being fundamentally attached to the land of their ancestors (ko au te whenua, ko te whenua ko au - I am the land and the land is me);

- which place the spiritual domain as a part of everyday life and not as a category conveniently positioned as a "day of rest" (ko te mea timatanga me te mea mutunga, ko te karakia - karakia at the beginning and end of all things); and

- which prioritise the particular over the universal, the subjective over the objective, and the relativist over the absolutist.

Unfortunately, these same indigenous peoples also share in common the negative as well as the positive effects of European colonialism. It is the former that attract researchers, politicians and bureaucrats. I suppose it is the problematic nature of the assimilative process that makes the negative effects attractive. Colonialism has worked "successfully" for some Māori - why not the others? What else do we need to do to get these others to fit in? Hence we have the research project.

I am taking considerable space to answer this question because it is statements like those made by Linda Smith (1996) that are taken by many Pākehā as being ungrateful and even unfair. They catch in the throat of those researchers/politicians/bureaucrats who have at times spent years working in the interests of indigenous communities and then to have their efforts besmirched and disqualified on the grounds of bias or prejudice. They find that difficult to accept, as though that disqualification was in some way equivalent to the conditions of separation experienced by Māori, or Pacific, or indigenous persons.

The negative effects of colonisation on indigenous peoples are similar everywhere:

- educational under-achievement (not succeeding to expectations);

- irregular school attendance and absenteeism;

- volatile behaviour; and

- withdrawal behaviour.

These are some of the more common characteristics associated with Māori and other indigenous groups within the schooling literature. But in the broader social sphere, the syndrome of behaviours emerging from the schooling experience take on a profoundly damaging dimension as evidenced in the unacceptably high levels of criminality, alcoholic and gambling abuse, violence against persons and property, self-mutilation and suicide. All of these themes are potential and actual areas for research. Some have been researched many times over a number of years.

Benefits accruing to indigenous peoples as a result of such research are perceived by those groups as relatively negligible. The conditions of separation remain, and as a consequence the negative behaviours get reproduced from one generation to the next. Why? One reason is that there are not enough indigenous people who become researchers/ politicians/bureaucrats, who then might be able to influence other researchers/politicians/bureaucrats about the inner-life of being Māori, Fijian, or Solomon Islander. Why don't they? Because one must succeed academically to begin with. Then one must see activities such as researching, allocating resources, and policy writing as worthwhile activities. The indigenous and human rights movements of the last 40 years is testimony to this growing access. For example, among Māori there have been gradual increases in these three careers, but in the last decade numbers have jumped significantly, although still far from being in relative proportion to mainstream Pākehā. The reasons for the increases are located in structural interventions, such as: masters level courses on research (like RAP) being offered in tertiary institutions; Waitangi Tribunal claims being investigated at the level of whanau and hapu (family and community); tribal investments in education as found in Tainui, Kai Tahu and Tuwharetoa; and post-graduate mentoring 
programmes like the national and international MAI (Maori and Indigenous) Project located in Auckland, Waikato, Wellington, Hawaii, Alaska, Vancouver; and so on.

KS: For peoples of the Pacific, this was true during the colonial period but it remains true, and, unfortunately, is considerably widespread today. Pacific peoples, from the tiny atolls of Tokelau to those living in the mountains of Papua New Guinea, are still "subjects" of research, mostly by outsiders, including New Zealanders, Australians and others. In certain fields of study, the major beneficiaries of research are not the "researched" but rather, the university researcher, development "specialist" and the Island-hopping, brief-case carrying consultant, who gather information, create what they collect as knowledge, and position themselves as "experts" on Pacific communities.

In New Zealand, the institution that benefits most from research in Pacific communities is the university, which houses volumes of research reports, books and non-print media, as well as "critical masses" of knowledgeable people in education, development, history, geography, anthropology and political science of the various Pacific Island countries. In return, the university has not used its expertise and services, partially obtained from Pacific-derived experiences and scholarship, to advance the cause of those "researched" within Pacific communities. What, for instance, did New Zealand anthropology departments do for the Polynesian community of Tikopia, following the devastating cyclone in early 2003, given that the study of Tikopia society is part of basic anthropology courses at university? What has been the university community's contribution to assisting the Fiji communities deal with the coups, or Solomon communities with their ethnic and national crises? What seems obvious to me is that the New Zealand research community has failed to reciprocate in its relationships with Pacific communities. In particular, New Zealand universities have failed to be relevant to Pacific communities and have not used their combined power-position to help Pacific communities meet the challenges of modern times.

It is not all negative. All knowledge, irrespective of who creates it, is of potential use. The opportunity exists for Pacific peoples to use the research done on and about them in ways that may be of benefit to their communities. Currently, research reports by outsiders are inaccessible because they are not written for Pacific audiences and are stored outside the Pacific. This, fortunately, is a temporary constraint. Over time, Pacific peoples will be able to access and use the research, for a wide range of purposes, towards improving the lives of their own communities.

\section{Q4. What is research, and what is the purpose of educational research that this course prioritises?}

KS: A clear definition of research is one of the challenges faced by this course. For Pacific peoples, research is the rigorous and purposive investigation of specific contextual knowledge about, from and on Pacific peoples and the issues affecting their lives (Sanga \& Pasikale, 2002). The authors go on to suggest that the rigour is attained through the application of ways of thinking, methods of collecting, recording, interpreting, using and reporting data that is context-embedded and consistent with the knowledge being sought and the socio-cultural and philosophical context. This is similar to Watson-Gegeo \& Gegeo's (1999) indigenous epistemology, which, according to these authors, is a cultural group's ways of thinking, creating knowledge, reformulating that knowledge using its own discourses and media of communication and anchoring the truth of that discourse in its culture. An underlying motive for research must be a positive "good" to the community being researched. Towards this end, priority must be given to ensuring that there is a better linkage between research and the educational progress of Pacific peoples.

It is commonly stated that educational research to date has not resulted in convincing improvements in the educational standards of Pacific peoples. This may in part, be explained by our refusal to appreciate specificity as a phenomenon, and our inability to use appropriate tools of logic, method and reporting that are consistent with the specific situation being studied. In this course, we encourage a critique of current fundamental assumptions of research, its policies and practices, its measures of control and legitimacy, its instrumentations and management.

WP: Being consistent with what I have already stated earlier, it should be obvious that educational research in RAP needs to accommodate both quantitative and qualitative approaches. As two sides of the same coin, complementary methodologies will likely portray the most accurate picture of how the world is perceived and how we can best come to understand it. The problem is that qualitative 
research struggles for acceptance at the level of scientific enquiry. I'll have more to say about this later, but in the meantime RAP prioritises qualitative approaches to research for two reasons. Firstly, because of the specific nature of the research questions being asked in Māori and Pacific education (what is the issue of identity in relation to performance? What counts as knowledge? Curriculum? Pedagogy? Evaluation? What is the effect of colonialism on schooling?) require face-to-face interpretive data collection.. The point about this sort of data collection is that despite the attempts at objectivity, people tend to like people like themselves, even in research. If Maori people feel they have not had a fair deal as a result of the research carried out on them, it should not be surprising that they might welcome a different sort of researcher, for example, one who is Maori. The second reason for prioritising qualitative approaches in RAP is that the underlying values of the researcher and the process are made explicit. Students come to understand where these values are coherent, and where they are not congruous with indigenous ways of knowing, seeing, and doing.

The purpose of RAP is to prepare students to conduct research in Màori and Pacific education. We think the best way to do that is to ensure that they know how to critique research already done in the field, and that they have a philosophical and theoretical understanding of qualitative research and its relationship with quantitative approaches. We also take the view that something of the ontological position of Māori and Pacific peoples must be part of the whole package of study - hence the requirement to include the articulation of indigenous knowledges.

\section{Q5. What are some of the practical challenges facing students studying} Research as Praxis?

WP: The limited resources available in the field are a major constraint. Māori and Pacific researchers, especially in the education context, are difficult to come by, although this is improving gradually at this moment. With only a handful of researchers there can only be a limited supply of research documentation, which gives us a minimal literature and experiential base. Broadening the research base to include other indigenous peoples such as Inuit and American Indian provides a much increased resource pool, but then loses something of the Māori/Pacific focus.
Because the majority of our students are full-time teachers and part-time students who are encouraged to choose topics for their assignments which are of practical use for them in their classrooms, almost without exception they select projects that require qualitative methodologies. This has probably as much to do with the nature of what goes on in classrooms as it has to do with the choice of research topics.

Another challenge has to do with the philosophical and critical sociological edge given to the course by its lecturers. For whatever reasons, too few students come into this course with academic backgrounds in either philosophy of education or in critical analysis. Students are thrown into the deep end in these studies and those who cope with it make insightful contributions through their assignments to Māori and Pacific educational research. Those who are confounded by the philosophy of education and critical analysis remain bewildered by the terminology, and progress little beyond informed description of Māori and Pacific students in some area of education. An example of this challenge is highlighted in discussions around the Peter Munz review and critique (1999) of Linda Smith's Decolonising Methodologies and an article on Anne Salmond's Two Worlds. It could be argued that the critical factor separating Smith and Salmond's research from that of Munz is located in the debate between the positivist legacy in social science (with the need to satisfy criteria such as internal and external validity), and the relativist ontology of constructivism which sets out to meet criteria of trustworthiness and authenticity. Both sets of criteria are established in order to judge the "goodness" or "quality" of an inquiry. It is extremely difficult to participate in the debate if one does not comprehend the key arguments of positivism and constructivism.

To really do justice to RAP the course needs to run for a full year, with eight or ten blocks rather than the six we have at present. (To accommodate students working full-time, the course is delivered in four two-hour sessions on a Friday evening and all day Saturday, six times over two trimesters. Each of these is called a block).

KS: $\quad$ There are challenges faced by all students and there are those faced by certain types of students only, and not others. Penetito has covered well some of the general challenges. I shall limit myself to an additional general challenge and one particular one.

All students face the challenge relating to the fact that this course sits within a University research context which is largely oriented 
towards conventional research. Beyond this course, students, as yet, cannot take further courses, based on this philosophical orientation, making it extremely constraining to engage with the university towards challenging its research culture.

Particularly for those Māori and Pacific students who are culturally literate, RAP offers a philosophical and theoretical grounding for indigenous, Māori and Pacific research. Understandably, such students are excited about RAP, but the course is constrained by factors of time, resources and focus, and does not allow such students to "do" indigenous/Māori/Pasifika epistemology, under our guidance. For these students, the challenge relates to what to do with the RAP experience, how to create Pasifika knowledge, how to articulate Pasifika methodologies, logic and more.

Q6. The philosophical debates cannot be avoided and should not be. What criteria do you think are appropriate for judging the goodness or quality of an inquiry?

KS: For Pacific research, quality is measured in a number of ways, including the extent to which research:

- maintains the mana of the researched and the researcher;

- enhances enduring relationships between the research and the researcher;

- is reciprocal for all parties involved;

- facilitates Pacific capacity and control of the process, outcomes and agenda;

- is Tongan, Samoan, Tokelauan and Pasifika in logic, method, reporting, experience and result.

WP: To keep my comments at a general level there are three points I think are most appropriate.

Firstly, is the notion that research must be seen to lead to positive outcomes for those who have been the subject of research, that is, research must contribute to their development as a group as well as individuals.

Secondly, is the notion that research is always an ethical concern because it deals with people's internalised values. In the words of the development scholar Denis Goulet:
Total integrated patterns of value cannot be obtained if people are treated as mere objects of observation or of interrogation. They must engage in the process of studying their own values as subjects, as active judges of the study undertaken. (1995, p. 29)

The third point I would emphasise concerns itself with the question of what counts as knowledge, how that differs from belief, and the role of experience? These are questions too important to be left to philosophers and theorists. Researchers in Māori and Pacific education are strategically placed to seek answers to these questions from their own communities.

\section{Concluding remarks}

In modern society neither (a) enculturation nor (b) socialisation is sufficient in itself, while (c)education cannot be realised for most without the successful integration of (a) and (b) - that is, there will always be some sort of cognitive, emotional or cultural gap. Successful integration depends on both (a) and (b) being retained as separate but inter-linked entities. To diminish either (a) or (b) is to fail the integrative and inclusive potential of the educative process. In Māori/Pacific education in New Zealand, evidence of this failure is far in excess of what is generally acceptable. Where the enculturation process remains the predominant focus, individuals can be seen as highly valued members within the local community such as kaumatua (elders) within Māori communities. But then this narrow definition flies in the face of our integrative function for what counts as education.

Where the socialisation process of mainstream schooling predominates, the over-powering influence of the universalisation norm might operate successfully for some students, but the cost is a separation from the values, norms and customs of the local community, thus defeating once again the inclusive purpose of what it means to be educated.

The educative process is both the means and the end of drawing together the values, norms and customs of the local and the universal. Education is both the "way" and the "goal". An education which does not help a Tokelauan "to be" a Tokelauan is not an education. An education of a Ngati Haua person which is, at the outset, ignorant of the significance of what it means "to be" a Ngati Haua person cannot be fully educative of that person. A teacher, however, cannot know about all the local communities represented within her class, but what she 
must do is understand the importance of the place of local communities to her students and to learn as much about each of them as she is capable of. She needs to help her students use as much of their local knowledge as they choose, along with the universal knowledge of the mainstream curriculum as a natural part of their everyday schooling.

All research, according to Trochim (1999), is based on assumptions about how the world is perceived and how we can best come to understand it. Thus have developed philosophical schools of thought such as positivism, relativism, constructivism, and so on. In the RAP course we have tried to avoid, wherever possible, attaching ourselves to any particular school of thought (it is said, the problem of attaching to any -ism is that one tends to become narrowed to arguing against other -isms and losing the integrity of the field one is trying to develop). On the other hand, in order to read and comprehend the research literature, one needs to be familiar with the selection of that literature.

The assumption we made about RAP is that it is at an early stage of its formal development with an absolutely minimal literature and practising resource base. What we do know is that education through formal schooling in New Zealand, for the larger proportion of Māori and Pacific students is at worst an alienating experience and at best fragmentary, that is, the majority of Māori and Pacific students in the schooling system are either completely "switched-off" by that experience or are ambivalent and "don't know where they stand."

Traditionally, most educational research is psychologically oriented, functionalist and positivist. The journals, text books, and reports on educational research are full of such studies. The articles tend to focus on individuals, their concern is mainly with providing explanations of the status quo, while the methodology is commonly out of the quantitative domain. New ideas in social science, at least for education, such as the sociology of knowledge, social construction, and phenomenology introduced new approaches to research which were generated from very different value systems and world views (Smith, 1999, p. 167). Māori, Pacific and other indigenous researchers gradually came onto the scene and began to see the possibilities inherent in another form of research, one in which the questions they were asking could be researched in methods they felt confident in using. Most of the research done by Māori, Pacific and other indigenous researchers in the contemporary world is qualitative in nature, but our concern in RAP is to ensure that our students must continuously face the ethical issue inherent in having "one foot inside and another outside" the system.
We leave the last word to Denis Goulet:

Development ethics rests on the epistemological premise that the study of the human condition is valid only when it takes place simultaneously on the level of positive science and on the evaluative level of philosophy. (1995, p. 14)

\section{References}

Bishop, Russell. (1996). Collaborative research stories Whakawhanaungatanga. Palmerston North: Dunmore Press.

Freire, Paulo. (1977). Pedagogy of the oppressed. London: Penguin.

Goulet, Denis. (1995). Development ethics: A guide to theory and practice. London: Zed Books.

Guba, E. G., \& Lincoln, Y. S. (1994). Competing paradigms in qualitative research. In N. K. Denzin \& Y. S. Lincoln (Eds.), Handbook of qualitative research (pp. 105-117). Thousand Oaks, CA: Sage Publications.

Massey University. (1998). Proceedings of Te Oru Rangahau, Māori Research and Development Conference, Palmerston North, July 7-9.

Munz, Peter. (1999). Open and closed research. New Zealand Books - A Review, 9(5), 6.

Munz, Peter. (1994). The two worlds of Anne Salmond in postmodern fancy-dress. The New Zealand Journal of History, 28(1), 60-75.

Roughan, J. (2002). The economy dictates the school curriculum. In F. Pene, A. Taufe'ulungaki, \& C. Benson (Eds.), Tree of opportunity: Rethinking Pacific education (pp. 48-51). Suva: University of the South Pacific.

Royal, Te A. Charles. (1992).Te haurapa: An introduction to researching tribal histories and traditions. Wellington: Bridget Williams Books Ltd. \& Historical Branch, Department of Internal Affairs.

Sanga, K., \& Pasikale, A. (2002). Research for Pacific empowerment: Guidelines for researching with Pacific communities. Paper presented at the Pacific Economic Symposium, Auckland, July 16-18.

Smith, Linda T. (1999). Decolonising methodologies: Research and indigenous peoples. London \& New York: Zed Books.

Strike, Kenneth A. (1989). Liberal justice and the Marxist critique of education - A study of conflicting research programmes. New York \& London: Routledge. 
Taufe'ulungaki, A. (2002). Pacific education: Are there alternatives? In F. Pene, A. Taufe'ulungaki, \& C. Benson (Eds.), Tree of opportunity: Rethinking Pacific education (pp. 5-21). Suva: University of the South Pacific.

Thaman, K. (2002). Towards cultural democracy in Pacific education: An imperative for the 21st Century. In F. Pene, A. Taufe' ulungaki, \& C. Benson (Eds.), Tree of opportunity: Rethinking Pacific education (pp. 2230). Suva: University of the South Pacific.

Trochim, William M. K. (1999). Research methods knowledge base (2nd ed.). <trochim.human.cornell.edu/kb/positvsm.htm>

Watson-Gegeo, A. \& Gegeo, D. (1999). Culture, discourse and indigenous epistemology: Transcending current models in language planning and policy. In Thom Huebner \& Kathryn Davis (Eds.), Sociopolitical Perspectives on Language Policy and Planning in the USA (pp. 99-116). Amsterdam: John Benjamin.

\section{The authors}

Wally Penetito (Tainui) is Senior Lecturer in Education and Joint Director of He Parekereke: Institute for Research and Development in Maori and Pacific Education at Victoria University of Wellington. His research interests are in the politics of consultation, the sociology of pedagogy, indigenous philosophies, and Maori and Pacific educational research. In earlier years he taught in primary schools, was an adviser to schools, a public servant in the Department of Education and the Education Review Office, an associate principal of Wellington College of Education, and a project manager in the Ministry of Education.

Kabini Sanga is an educator from the Solomons, currently a senior lecturer at Victoria University of Wellington, where he teaches Pacific education, indigenous research, and educational leadership. His doctoral research at the University of Saskatchewan in Canada was on international policy. 